Hugo Echagüe

\title{
La pregunta de la teoría ${ }^{1}$
}

Universidad Nacional del Litoral

Paul De Man (1986: 13) centra la interrogación de la teoría

literaria en la cuestión de qué es la literatura. ${ }^{2}$ Así dice:

Una toma de postura en general sobre la teoría literaria no debería, en teoría, partir de consideraciones pragmáticas. Debería tratar cuestiones como la definición de la literatura (¿qué es la literatura?) y debatir la distinción entre los usos literarios y no literarios del lenguaje, así como entre las formas artísticas literarias y las no verbales.

Agrega que se debería continuar con taxonomías de géneros literarios y reglas que se desprendan de estas clasificaciones, ya desde una fenomenología de la actividad literaria como escritura, lectura, o ambas, o de la obra literaria como producto. Pero en todos los casos, señala, dicha teoría se enfrentaría con dificultades insalvables y no podría evitar caer en total confusión, ya que es imposible establecer los límites de la cuestión. Sin embargo, añade, estas dificultades no han impedido a diversos autores seguir caminos teóricos y no pragmáticos con considerable éxito, aunque esta posibilidad dependa

del poder de un sistema (filosófico, religioso o ideológico) que puede mantenerse implícito pero que determina una concepción a priori de lo que es 'literario' partiendo de las premisas del sistema más que de la cosa literaria misma -si dicha 'cosa' existe realmente. (13-14)

Así se resigna a esta imposibilidad de definir la cosa misma de la literatura y admite que "si la condición de existencia de una entidad es en sí misma particularmente crítica, entonces la teoría de esta entidad está destinada a caer en lo pragmático" (14). A partir de allí, desarrolla su notable ensayo sobre la resistencia a la teoría.

Proponemos ahora que las preguntas no contestadas o renunciadas permanecen, por ello mismo, vigentes y acuciantes, por lo que requieren, al menos, un análisis detallado. Es lo que pretendemos llevar a la reflexión en lo que sigue, pues, ya en los casos en que un teórico haya tenido éxito siguiendo un determinado sistema que provea a priori una definición de lo literario, o bien cuando una determinada dirección se resigna a lo pragmático, no dejan aun así de presuponer la pregunta que ha sido dejada de lado. Preguntamos por las condiciones de posibilidad en general de la pregunta pues su presuposición misma es ya una respuesta que se anticipa a una problemática que ha de ser desplegada.

\section{La historia de una pregunta}

La pregunta ¿qué es la literatura? tiene una forma señalada y, en cuanto tal, una procedencia. Lejos de ser una entre otras, inocente y espontánea, dice, para nuestros fines, más de sí misma 
que las respuestas que puedan o no serle consecuentes. La pregunta por el por qué es la pregunta por excelencia y responde al modo filosófico predominante desde Platón. Es la pregunta por la esencia, el $\tau \iota \varepsilon \sigma \tau \imath v$. Quien así interroga se inscribe desde ya en un ámbito determinado del preguntar: el de la interrogación por la esencia, el origen y el fundamento. Va en busca del $\varepsilon \imath \delta o \zeta$, la $\imath \delta \varepsilon \alpha$, la $o v \sigma \iota \alpha$, y así no es una pregunta entre otras sino que se mueve ella misma en el circuito de cierta modalidad del pensamiento que rige tal preguntar. De allí que atendiendo al modo de este preguntar, podríamos lograr acaso precisiones más relevantes acerca de en qué dirección mover nuestra reflexión antes que procurarnos una determinada respuesta que se arrumbaría, junto a otras, en el devenir de la historia de una problemática, en este caso, la de la literatura y su teoría.

¿Qué dice esta pregunta de sí misma? Es, apuntamos, la pregunta por la esencia, la quidditas, la $\mu о \rho \varphi \eta$. Dice Heidegger (1960:3): "el modo en que todavía hoy preguntamos, es griego. Preguntamos: ¿Qué es...? Esto suena en griego: $\tau \iota$ $\varepsilon \sigma \tau \iota \nu$ ". Y agrega: "Lo que el qué significa se lo llama el quid est, $\tau \imath$ - quid: la quidditas, la Washeit" (ibid.). Esto ubica en una dirección, en una tradición, nuestra pregunta sobre qué es la literatura; es la de la pregunta por la esencia, por lo que esencialmente sea la literatura. $\mathrm{Y}$ así señala:

Desde hace mucho tiempo se suele caracterizar como pregunta por la esencia la pregunta acerca de qué sea algo. La pregunta por la esencia se despierta cada vez que se ha oscurecido y enredado aquello por cuya esencia se pregunta, cuando al mismo tiempo se ha vuelto vacilante, o aun se ha quebrantado, la relación del hombre con lo preguntado. (ibid.)

Entonces, deberíamos concluir, la cuestión de qué sea la literatura da cuenta de un estado de cosas esencialmente problemático, de un ya no saber a qué nos estamos refiriendo con la palabra literatura aun cuando diariamente hablemos de literatura y hasta pretendamos teorizar sobre ella.

Sin embargo, la teoría debería partir, como señala Paul De Man, de esta pregunta. ¿Debería contestarla? ¿Por qué no puede? ¿Por qué finalmente nos resignamos a lo pragmático, como si dijésemos "no podemos contestarla pero, después de todo, quién no sabe lo que es la literatura"? Y sin embargo, no parece que lo sepamos. Podríamos preguntar al menos por qué, qué circunstancia, particularmente compleja, obstruye nuestro camino hacia una respuesta, declarándola incluso, finalmente, innecesaria. Podría ser entonces oportuna la pregunta acerca de por qué no sería relevante esta interrogación y por qué deberíamos, o podríamos, dejarla de lado. Aun así, esto no podría suceder sin un previo plantear la pregunta y las condiciones en que ésta se formula, porque lo que no podríamos hacer es silenciarla sin más. Preguntamos entonces por la posibilidad de esta pregunta.

La hemos delimitado; ella pertenece a una tradición, aquella que se despliega preguntando qué es algo, es decir, cuál es su esencia. Este planteo parece implicar la cuestión del origen, del principio, de lo incontaminado que algo habría sido en su comienzo. La pregunta por la esencia se convierte así en la pregunta por el origen. Este sería así lo que funda una historia, la cual aparecería entonces como la contaminación, la confusión; el retorno al origen sería, entonces, el acceso a la pureza, como se dice, original. Así, origen, principio, de un lado, e historia, del otro, se opondrían, como lo puro a lo contaminado y desviado. Sin embargo, origen y principio tienen también su propia historia, en tanto conceptos. 


\section{Origen y genealogía}

Foucault (1992:13), retomando a Nietzsche, opone origen a genealogía. Así dice:

La genealogía no se opone a la historia como la visión altiva y profunda del filósofo se opone a la mirada de topo del sabio; se opone, por el contrario, al desplegamiento metahistórico de las significaciones ideales y de las indefinidas teleologías. Se opone a la búsqueda del "origen".

Nietzsche destituye la preeminencia de todo origen, lo señala como "artimaña”, "artificio", "secreto de fabricación”, “trabajo de magia negra” (ibid.: 15). Nietzsche, inspirador -el primero- de la deconstrucción, ${ }^{3}$ rechaza la búsqueda del “origen” (Ursprung), ya que eso sería “tratar de encontrar 'lo que ya existía', el 'eso mismo' de una imagen exactamente adecuada a sí misma” (ibid.: 17-18). Es decir, finalmente, una esencia, una quidditas. ¿Qué descubre, sin embargo, el genealogista?

Que detrás de las cosas hay "otra cosa bien distinta": no su secreto esencial y sin fecha, sino el secreto de que no tienen esencia, o de que su esencia fue construida pieza a pieza a partir de figuras extrañas a ella. ¿¿La razón? Que ha nacido de una forma del todo "razonable" -del azar-. (18)

Así se deconstruye -se dice ahora- la idea del origen, así como lo puro y puntual se enfrenta a lo superpuesto, al pastiche, al collage de ideas e intereses, de imágenes, de metáforas que han perdido el recuerdo de su motivación y se alzan con aspecto presuntamente incólume. Así, en Nietzsche:

¿Qué es entonces la verdad? Una hueste en movimiento de metáforas, metonimias, antropomorfismos, en resumidas cuentas, una suma de relaciones humanas que han sido realzadas, extrapoladas y adornadas poética y retóricamente y que, después de un prolongado uso, un pueblo considera firmes, canónicas y vinculantes; las verdades son ilusiones de las que se ha olvidado que lo son; metáforas que se han vuelto gastadas y sin fuerza sensible, monedas que han perdido su troquelado y no son ahora ya consideradas como monedas sino como metal. (1873:25)

Retengamos, de entre todas las repercusiones que puede tener este párrafo, que, a los fines que aquí nos interesan, es así como aparece la "procedencia” (Herkunft) que, señala Foucault, Nietzsche opone al "origen” (Ursprung), como lo contingente se opone a lo presuntamente destinal.

¿Qué pasa entre tanto con nuestra pregunta? ¿Nos contentaríamos acaso, ahora y en consecuencia, con remitirla a coyunturas y consensos más o menos historicistas, como parecen sugerir, desde distintos presupuestos Even-Zohar (1972; 1990; 1986) y Jonathan Culler (1989)? Sin embargo, la cuestión no se deja aplanar tan fácilmente en el mero consenso de los especialistas ni en las alternativas del polisistema. Buscamos otra aproximación.

\section{Rizomas}

En un ámbito similar transcurre el pensar de Deleuze/Guattari (1976:10) en tanto negación de todo origen, esencia y fundamento:

Un libro no tiene objeto ni sujeto, está hecho de materias diversamente formadas, de fechas y de velocidades muy diferentes. Cuando se atribuye el libro a un sujeto, se está descuidando ese trabajo de las materias, y la exterioridad de sus relaciones. Se está fabricando un buen Dios para movimientos geológicos. 
Esto es, se lo remite a una profundidad, un autor, un origen, un centro. Es probable que a esta altura de la reflexión la pregunta que parecía plantearse espontáneamente como la pregunta por la literatura -la interrogación por su qué es, por su esencia- se vea radicalmente transformada al cambiar la perspectiva de una cuestión que ahora aparece ilusoria, solidaria de fantasmagorías y de espectros. Así señalan:

Nunca hay que preguntar qué quiere decir un libro, significado o significante, en un libro no hay nada que comprender, tan sólo hay que preguntarse con qué funciona, en conexión con qué hace pasar o no intensidades, en qué multiplicidades introduce y metamorfosea la suya, con qué cuerpos sin órganos hace converger el suyo. Un libro sólo existe gracias al afuera y al exterior. (ibid.: 11)

No tiene un centro, un interior, un origen, que funden un querer-decir. La impugnación de la interpretación implica a la esencialidad: "No hay nada que comprender". Así, poco a poco la pregunta por la esencia empieza a revelarse como una pregunta ilusoria y empieza a ser reemplazada por la pregunta acerca del dónde y tal vez el cuándo y el cómo de la literatura: dónde un texto es literario y cuándo y de qué modo: “(...) cuando se escribe, lo único verdaderamente importante es saber con qué otra máquina la máquina literaria puede ser conectada y deber serlo para que funcione" (ibid.). La pregunta por el origen desaparece -o mejor, se transforma- junto a la interrogación por la esencia pues sólo eso llamado literatura habilitó la remisión a un presunto origen antes del cual no la habría habido. La pregunta pasa a ser irrelevante -y además, incontestable; más allá de coyunturales aproximaciones- y se convierte en la cuestión acerca del lugar, el momento y el modo de eso llamado literatura.

\section{Literaturidad...}

Después de todo fue en el comienzo de la teoría que se intentó cercar eso de lo literario y se lo llamó literaturidad. Hasta ahora, como dice Culler (1989), nadie la ha hallado y podríamos presuponer que es así debido a que su problemática se instala, como apuntan Deleuze/Guattari (1976) y Foucault (1986), en un afuera de toda esencia y origen y así, de todo discurso que la abarque, de todo metalenguaje, tal vez en una différance (Derrida 1968). Pero lo que no se puede delimitar, se desborda, lo invade todo, es sin-límites. ¿Entonces todo sería literatura? ¿Y a la vez, nada lo sería? Tal vez no, pero si ésta es sinlímites, esta descripción negativa podría ser también una de las razones de la imposibilidad de la pregunta por la esencia, ya que no podría delimitarse y consistiría - entonces- en un afuera no-original:

En resumen, creemos que la escritura nunca se hará suficientemente en nombre de un afuera. El afuera carece de imagen, de significación, de subjetividad. El libro agenciamiento con el afuera frente al libro imagen del mundo, el libro-rizoma, y no el libro dicotómico, pivotante o fasciculado. (Deleuze/Guattari 1976:52)

Así Deleuze/Guattari instalan la dicotomía de árbol y rizoma; origen y devenir. El rizoma fluye, se traslada, transgrede, va hacia ninguna parte desde ningún lugar. Sin fundamento, más allá de sí mismo, sin arraigo en suelo y raíz. Sólo afuera. 


\section{Y más allá}

Es probable que si vaciásemos a la llamada literatura de todos los discursos y sistemas que la habitan: narrativo-ficcional, poético, estético, político, social, entre otros, nos quedásemos con nada. Adiós, literaturidad. Por qué no, la literatura podría ser también el vaciamiento de todos los discursos, su cáscara vacía; su propia ausencia. Como señalan Deleuze/Parnet (1977:131):

Cuando se considera aisladamente un flujo de escritura lógicamente lo único que puede ocurrir es que gire sobre sí mismo, que caiga en un agujero negro en el que lo único que se oirá hasta la saciedad será el eco de la pregunta “¿qué es escribir?, ¿qué es escribir?”, sin que jamás se obtenga una respuesta.

Pidamos una metáfora a la música: la literatura podría ser el contrapunto de diversas voces desde varios ámbitos del afuera que eventualmente generarían, en algunos puntos, armonías más o menos consonantes o disonantes. La literaturidad sería así un ensamblaje de discursos y no una especificidad; aunque no consistiría sin embargo en una simple yuxtaposición. Cada uno de estos discursos (filosófico, político, histórico) sería una línea melódica que se desenvuelva en contrapunto con respecto a las otras; los acordes que eventualmente formasen podrían ser las intensidades donde lo que llamamos literatura emerge con mayor grado de aparente evidencia, con lo cual se abren otros interrogantes referidos a cómo se ensamblan las voces; qué leyes de armonía y contrapunto las rigen. Y así, de qué orden serían lo ficcional, lo poético; ya no esencias, sino armonías y juegos de voces; el resultado del ensamble, no un agregado o una cualidad previa; sólo nombres y etiquetas móviles sometidos a metamorfosis imprevisibles, a un devenir incesante que intercambia lugares, disloca fronteras, invade territorios. No una quidditas, sino un ensamble aleatorio, fantasmal, como la verdad en el párrafo de Nietzsche. Así Barthes (1970: 22-24) enlaza la figura del texto que él llama clásico o legible con la tonalidad, así como vincula el desciframiento de enigmas con el arte de la fuga. El texto escribible debería ser atonal.

Todo esto sería posible, pero entre tanto la pregunta de la teoría ha sufrido una transformación radical: dónde es la literatura; cuándo y cómo cierto segmento, superposición, mixtura, confluencia de discursos, pueden ser juzgados como literarios sin remisión a un qué original, sino a construcción, emergencia, collage; encuentros y desencuentros; armonías; voces que fugan en el vacío hacia ninguna parte pero que aparecen en cualquier lugar y momento. Entonces habría que descubrir y describir los modos -aunque coyunturales y azarosos- de esos acoples, los pentagramas, las cartografías de esas constelaciones de discursos; su espaciamiento y su transcurso. Un caso conocido: dónde y cómo se cruzan y acuerdan lo narrativo con lo político, en nuestra literatura, desde el comienzo. Entre nosotros, lo literario no existió, como ya es sabido, nunca -o casi- fuera de esta aleación. Se podrían precisar los modos, en cada caso, de estos acordes; sus progresiones; los motivos y sus desarrollos probables.

\section{Y todavía...}

La metáfora de la música sirve para establecer que, sin embargo, estas confluencias no son meras sumas (esto + aquello): lo 
narrativo + lo político + lo filosófico. Se trata, en cambio, de un desbordamiento, de otra cosa que se logra a través de esas relaciones, armonías y contrapuntos. La literatura es ese desbordamiento discursivo que traspasa incesantemente sus propios límites, que, finalmente, no existen, no estaban allí antes de su emergencia. ${ }^{4}$ Donde hubo certezas, en un origen presunto, retrospectivamente supuesto, corre ahora el incesante discurrir de la literatura, en la apasionada mostración de una ausencia, de una des-fundamentación radical (que puede, eventualmente, proponerse como sutura de esta ausencia)..$^{5}$ Así, la literatura se vincularía con la retirada del mito, de la creencia; tal vez lo que está allí donde antes habría habido un fundamento; entonces sí procedería, en la experiencia del afuera, de Hölderlin, el poeta de la ausencia, y de Sade, el habla de la transgresión y el murmullo de los discursos (Foucault 1986: 18 ss). ${ }^{6}$ Entre tanto, lejos de padecer, como a veces aparenta, un agotamiento, se expande y desborda, aunque esparciendo a su paso la confusión de su des-fundamento y arriesgando su límite hasta la desaparición o metamorfosis. Dionisos es su ámbito, aunque también Orfeo, señala Foucault (1994a). Pero aún más, es el deseo de sí misma; es el desborde y la explosión. Esa otra cosa que nadie sabe lo que es, porque no tiene un qué, es lo que alguna vez se comenzó a llamar literatura. Habría que continuar, entonces, escribiendo su genealogía y sus cartografías, sus mapas y ramificaciones. La literatura sería entonces el desbordamiento mismo pero no desde un interior, de una presunta esencia, sino desde el afuera; como una cinta de Moebius, una superficie de una sola cara; un plus respecto de los discursos que supuestamente la integran. Eso, visible pero indefinible; simple, pero a la vez oblicuo y transversal, tal vez eso finalmente sea la buscada literatura que ya no es una forma sino un exceso, un devenir orgiástico, un perpetuo transcurrir, un fluir en nada; también, como la música, una "misteriosa forma del tiempo" (Borges); un dibujo en el vacío. Así, con el mismo gesto, que al desmitificar tiende un nuevo velo y recomienza su ciclo, volvemos al principio: "¿Qué es la literatura?”. Ahora diríamos que es su propia negación, su no-serliteratura como negación de una especificidad positiva y que se muestre afirmativamente. Es su ausencia de propiedad, de especificidad, lo que la hace surgir en un instante que sólo se sostiene interminablemente en su propio vacío, en su no-ser respecto de una presencia que no se dará aunque parezca anunciarse; es su ausencia en los discursos que la integran y en los que se niega. Es esa ausencia, ese vacío siempre indicado, señalado, lo que la vuelve una construcción utópica, una promesa indefinidamente diferida que no llega a una manifestación, porque es su propio hueco, el vacío de todo lenguaje a la vez que se enmascara en todos ellos. Así enmascarada avanza en su proyecto siempre inconcluso, imposible, en la página en blanco de Mallarmé, en el silencio de Rimbaud, en el aplazamiento de Proust, en el infinito de Kafka. 
${ }^{1}$ El texto que sigue es una reescritura de una ponencia leída en el III Congreso Internacional de Teoría y Crítica Literaria, Universidad Nacional de Rosario, agosto de 2002.

${ }^{2}$ Obviamente, no es el único. V. Culler (1989); Foucault (1994a), entre otros.

${ }^{3}$ Reconocido en tal sentido por De Man (1979).

${ }^{4}$ Para Derrida (1971, pp. 79-80), el texto es el desbordamiento, incluso más allá y antes de toda "literatura".

${ }^{5}$ Cf. a este respecto Badiou, 1989.

${ }^{6}$ En relación con el comienzo de la institución literatura, al nombre de Sade suma el de Chateaubriand (Foucault 1994a:70 ss). Sobre Hölderlin y este comienzo, V. también Foucault 1994b, p. 148.

\section{Bibliografía}

Barthes, R. (1970): $S / Z$, Madrid, Siglo XXI.

BADIOU, A. (1989): Manifiesto por la filosofía, Madrid, Cátedra.

Culler, J. (1989): “La literaturidad” en Angenot, Fokkema y otros: Teoría literaria, México, Siglo XXI.

Deleuze, G. (1976): Rizoma, Valencia, Pre-textos.

Deleuze, G. y Parnet, C. (1977): Diálogos, Valencia, Pre-textos.

De Man, P. (1979): "Retórica de tropos" y "Retórica de la persuasión" en Alegorías de la lectura, Barcelona, Lumen.

(1986): La resistencia a la teoría, Madrid, Visor.

Derrida, J. (1967): "El fin del libro y el comienzo de la escritura” en De la gramatología, México, Siglo XXI.

(1971): "Posiciones. Entrevista con Jean-Louis Houdebine y Guy Scarpeta" en Posiciones, Valencia, Pre-textos 1972.

(1968): "La différance" en Márgenes de la filosofia, Madrid, Cátedra, 1994. Even-Zohar, I. (1990a): El sistema literario, trad. de "The Literary System", "Poetics Today" 11:1: 27-44.

(1990b): Teoría del polisistema, traducción de Polysystem Theory, "Poetics Today" 11:1:9-26.

(1985): La buisqueda de leyes y sus implicaciones para el futuro de la ciencia de la literatura. Versión basada en la traducción de Navarro, D. en: "Criterios", 13-20, 1. 1985 - XII; 1986: 241-247.

Foucault, M. (1992): Nietzsche, la genealogía, la historia, Valencia, Pretextos, $2^{\text {a }}$ ed.

(1986): El pensamiento del afuera, Valencia, Pre-textos.

(1994a): "Lenguaje y literatura" en De lenguaje y literatura, Barcelona, Paidós, pp. 63-103.

(1994b): "El lenguaje al infinito" en De lenguaje y literatura, Barcelona, Paidós, pp. 143-155.

Heidegger, M. (1960): ¿Qué es eso de filosofía?, Buenos Aires, Sur. Nietzsche, F. (1873): Sobre verdad y mentira en sentido extramoral, Madrid, Tecnos, 1990. 